\title{
Caring in Conflict, Paradigms, and Health Systems
}

This is issue number one of volume two of the Christian Journal for Global Health, addressing some aspects of the theme Caring in Conflict. Mindful that conflict is a major feature of daily life for billions the world over, we invited papers that concern conflict on multiple levels: international, events in our environment, and interpersonal. It is perhaps early to hear reports from the response to the earthquakes in $\mathrm{Ne}$ pal, but Maha Asham tells us what it has been like for internally displaced refugees from the fighting in Iraq who have been cared for by Christians in Kurdish areas. Sangeeta Nair, Lois Joy Armstrong, and Philip Finny present a study on family conflict as the major underlying influence in suicide attempts in Northern Bihar, India. Dr. Sarah Nageshwari describes the rigors of health care delivery amid political and religious conflict in Kashmir. Dr David Stevens, speaking from his experience as a global health physician and chief executive officer of the Christian Medical and Dental Associations, contributes his wisdom on resolving interpersonal and institutional conflict.

Contributions on the theology and philosophy of missions and of global health continue to be a major interest of journal contributors and three articles in the current issue reflect this. Professor Raymond Downing provocatively makes the case that science had replaced spirituality in medical missions in the $19^{\text {th }}$ Century, at least partly as a consequence of disparaging African spiritual cosmology. Dr. Jose Miguel De Angulo and Luz Stella Losada offer an historical overview of paradigms in global health as they have evolved over the $20^{\text {th }}$ Century, pointing out how systems theory and the study of complexity have affected theory and practice. These provide a background for emerging paradigms in the $21^{\text {st }}$ Century. Chad Swanson and Brian Thacker provide an excellent introduction to systems thinking, and propose its application fruitfully to short-term health missions. Gnanaraj Jesudian is a surgeon in rural India and is in a position to describe the value and pitfalls of short-term medical work from the unique perspective of a host for better health care access, spiritual growth and research. His research meets a gaping need in the literature, and not all of what he has to say is congratulatory. Book reviews can be effective commentary on current issues, and Ronald Halbrooks' review of Health, Healing and the Church's Mission does this well.

The editors are pleased to be able, from time to time, to help disseminate practical advice on global health practice from experts in the field. Dr. Elvira Beracochea has written a short contribution on improving the quality of child healthcare as the first part of a series. Her article can be printed and used as an evaluation checklist in the field. We also intend to provide reports from conferences relevant to our readers. This issue contains summaries of the Engage Disability Conference held in New Delhi in September 2014 and the Medicine and Religion Conference held in Boston in March 2015 with hopes to remind us of the relevance of our faith to healthcare and the latest thinking in the global health community.

The editors are pleased at the continued flow of submissions to the journal; there are currently a number of articles still in the review process. We hope to encourage more articles describing original research, and will continue to waive the article processing charge for 2015 and possibly beyond with the support

May 2015. Christian Journal for Global Health 2(1): 1-2. 
of generous donors. We offer a strong team of reviewers to help authors less familiar with the preparation of such work. We are working on a procedure to help authors lacking access to an Institutional Review Board. This procedure will still maintain a high standard of ethical review for the journal, and when completed, will be described clearly on the website author guidelines.
Beside regular submissions, we are calling for papers related to Disability and Rehabilitation for the next issue. We encourage comments on the Disqus feature for articles of interest, feedback to the editors, and to let this resource be known among your respective circles. Engage and enjoy!

www.cjgh.org 